\title{
Breastfeeding Duration Is Associated With Growth Among Children Aged 0 to 23 Months; Analysis of the Zambia 2018 Demographic and Healthy Survey Data
}

Chiza Kumwenda ( $\boldsymbol{\sim}$ chiza.kumwenda@unza.zm )

University of Malawi College of Medicine

Lukonde Mwelwa Zgambo

University of Zambia School of Agricultural Sciences

Maryse Umugwaneza

University of Rwanda College of Medicine and Health Sciences

Dorothy Nthani

University of Zambia School of Agricultural Sciences

Hilda Nyambe Silavwe

National Institute for Scientific and Industrial Research

Keiron Audain

University of Zambia School of Agricultural Sciences

\section{Research}

Keywords: Breastfeeding duration, growth, infants, demographic and health survey, Zambia

Posted Date: January 19th, 2021

DOl: https://doi.org/10.21203/rs.3.rs-148598/v1

License: (c) (i) This work is licensed under a Creative Commons Attribution 4.0 International License.

Read Full License 


\section{Abstract}

\section{Background}

The World Health Organization recommends exclusive breastfeeding for the first 6 months and continued breastfeeding up to 24 months and beyond. Breastfeeding is beneficial for infant growth, development, and survival. Evidence on the association between breastfeeding duration and growth is not conclusive. The aim of the present study was to establish the association between breastfeeding duration and growth among infants and young children.

Methods

The study is based on data from the 2018 Zambia Demographic and Health Survey (ZDHS). The primary outcome for the study was height-for-age Z-score (HAZ). Association between HAZ and breastfeeding duration was assessed by using regression analysis.

Results

The overall mean \pm SD for HAZ was $-1.24 \pm 1.46$ and the median (interquartile range) breastfeeding duration was 9 (4-14 months). After controlling for potential confounders, breastfeeding duration was inversely associated with HAZ $(\beta=-0.07, p<0.001)$ and $\mathrm{WHZ}(\beta=-0.04, p<0.001)$. Path analysis demonstrated that the effect of breastfeeding duration is independent of child's birth weight and maternal perceived birth size. Other determinants of HAZ were child's weight and sex, while WHZ was predicted by maternal age, diarrhea episode and child's birth weight.

\section{Conclusion}

Breastfeeding duration is negatively associated with both HAZ and WHZ among Zambian children. However, the magnitudes of the association are quite small to be of clinical significance. Thus, breastfeeding should continue to be promoted, protected and supported from birth up to two years and beyond.

\section{Introduction}

Breastfeeding infants and young children up to 24 months and beyond is beneficial to the mother-infant dyad and the entire society at large (1). Optimal breastfeeding is associated with health, nutritional and developmental benefits for infants (2). Hence, it has been empirically shown that optimal breastfeeding is one of the most cost- effective interventions for prevention of malnutrition in children (3). Conversely, suboptimal breastfeeding practices increase the risk of malnutrition, morbidity, and mortality in infant and young children both in developed (4) and developing countries (5). Scaling up optimal breastfeeding to a near universal level has the potential to prevent up to 823000 deaths among children under five years and 20000 maternal deaths from breast cancer per year (1). According to the United Nations Children's Fund (UNICEF), optimal breastfeeding is described as initiating breastfeeding within the first 
hour of birth without discarding colostrum, exclusive breastfeeding for the first 6 months from birth and continued breastfeeding for 2 years or beyond, with the introduction of appropriate complementary feeding.

In Zambia, breastfeeding is almost universal. The most recent nationally representative data shows that almost $98 \%$ of children were breastfed in the last 2 years preceding the survey (6). On the other hand, only about $16 \%$ of children aged between $6-23$ months receive the minimum acceptable diet (meeting ageappropriate dietary diversity and frequency). At country level, there are substantial variations by province with respect to breastfeeding indicators and age-appropriate complementary feeding. For instance, timely initiation of breastfeeding is lowest in the northern province at $65.2 \%$ and highest in Northwestern province at $86.3 \%$ (6). Despite a national decline in stunting levels among children aged below five years from $40-35 \%$ between 2014 and 2018, these numbers remain unacceptably high.

Breast milk forms an important source of energy and high-quality nutrients for growth and development of infants and young children. Furthermore, breast milk contains bioactive components essential for the immune system development of the infants (7). Some of the bioactive compounds found in breast milk have been linked to promotion of linear growth in infants and young children (8). Despite the potential for breastfeeding to improve growth, there is still no consensus on whether continued breastfeeding from six months of age is associated with growth among infants and young children. Studies which demonstrated a positive association between breastfeeding and growth are characterized by methodological errors $(9,10)$, evidence of reverse causality has been reported in several epidemiological analyses linking breastfeeding and growth outcomes among infants and young children (11-13). To address these concerns, we explore the relationship between breastfeeding and nutritional status among children under the age of five years using a national representative sample.

\section{Methods}

\section{Study design and subjects}

The present study is based on data from a nationally representative data from the 2018 Zambia Demographic and Health Survey (ZDHS). The 2018 ZDHS was conducted by the Zambia Statistics Agency (ZSA) and the Ministry of Healthy in conjunction with ICF. The survey design and sampling has been described elsewhere (6). Briefly, the primary sampling unit was a household which was obtained using a stratified two stage sample design. The initial stage was aimed at sampling clusters from which eligible households were systematically sampled to obtain a total sample size of 13,625 households. Both men and women aged 15-49 from selected households whether permanent residents or visitors who stayed in the households the night before the survey were eligible to be interviewed. For the present study included living children aged between 0-23 months who had complete anthropometric data and infant and young child feeding variables. Permission to use the 2018 dataset was sought and obtained from the Demographic and Health Surveys (DHS) Program. The DHS protocols were all approved by 
relevant ethics institutional review boards in Zambia (Tropical Diseases Research Centre) as well as at ICF, thus for the current analysis no further ethical review was warranted.

\section{Variables}

\section{Outcome variables}

The primary outcome variable used to assess the relationship between breastfeeding and growth was height-for-age $Z$ (HAZ) considering that it is the main nutritional problem in Zambia. Weight-for-age $Z$ (WHZ) was used as a secondary outcome. Both HAZ and WHZ were calculated using the WHO child growth standards. Stunting and wasting were generated from the HAZ and WHZ scores as binary variables based on World Health Organization cut off points for malnutrition using anthropometric indices (<-2 standard deviations denoting presence of stunting or wasting).

\section{Predictor variables (main independent)}

To determine the association between continued breasting and growth, the main predictor variable used was duration of breastfeeding in months. Other independent variables included were; 1 ) child characteristics such as age, sex, birthweight, "size at birth", morbidity in the last two weeks-diarrhea, fever and cough; 2) maternal characteristics such as age, education level (No formal education, primary, secondary and higher); infant and young child feeding-dietary diversity based on eight food groups which included breast milk; grains, roots, and tubers; flesh foods (meat, fish, poultry, and liver/organ meat); eggs; legumes and nuts; dairy products (milk, yogurt, and cheese); vitamin A-rich fruits and vegetables; and other fruits and vegetables; $\mathbf{3}$ ) household variables including sex of the household head, marital status of the respondent, number of children under the age of five, literacy (ability to read or write), household size and wealth index. The ZDHS calculated household wealth index based on consumer goods owned by the household such as radio, television. refrigerator, bicycle, motorcycle, and car; housing construction materials used for making the house main floor, walls and the roof and types of water access and sanitation facilities. The household wealth scores were generated using the principal component analysis.

\section{Statistical analysis}

All statistical analyses were performed using Stata version 13 (version 13; STATA Corp, College Station, TX, USA). Before conducting any statistical analyses, sample weights were applied to address effects of two stage cluster sampling design to ensure that the results reflect representativeness of the children at national level (14). Furthermore, the analysis was stratified by age (all children 0-59 months and children 0-23 months) to eliminate what has been termed as partial exposure bias (15). All continuous variables were assessed for normality using Shapiro-Wilk test before running any statistical test. Associations were assessed using bivariate and multivariate analyses, the former was used to identify variables significantly associated with growth outcomes which were to be included in the latter analysis to 
establish the independent association between growth outcomes and each of the included variables. Pearson and multiple linear regression were used to assess correlation and independent association between growth and independent variables, respectively. Path analysis was conducted to assess hypothetical causal relationship between variables and their relationship with growth outcomes. For this purpose, three regression analyses were run to establish whether or not breastfeeding duration was a mediator or directly was associated with nutritional status. In one model breastfeeding duration was regressed on child's birth weight, maternal age and education. The level of statistical significance was set at $p<0.05$.

\section{Results}

\section{Sample characteristics}

Demographic characteristics of the sample are shown in Table 1. The proportion of girls in the sample was comparable to that of boys. The median age (IQR) for children was 9 (5-15) months. The children's median birthweight (IQR) was $3.1(2.8-3.5) \mathrm{kg}$. Incidence of diarrhea was low among children. The median maternal age was 26 years and most mothers had attended formal education up to primary school. Mothers were more likely to be rural resident and coming from households mostly headed by males. About two thirds of the households had access to clean water. 
Table 1

Sample characteristics

\begin{tabular}{|c|c|c|}
\hline Characteristic & $\mathbf{N}$ & $\%$ or Median (IQR) ${ }^{*}$ \\
\hline \multicolumn{3}{|l|}{ Child characteristics } \\
\hline Proportion of females & 1611 & 51.1 \\
\hline Age in months & 3116 & $9(5-15)$ \\
\hline \multicolumn{3}{|l|}{ Age categorized } \\
\hline$<6$ months & 971 & 32.4 \\
\hline $6-11$ months & 891 & 29.7 \\
\hline 12-18 months & 816 & 27.2 \\
\hline$>18$ months & 324 & 10.8 \\
\hline \multicolumn{3}{|l|}{ Perceived size at birth } \\
\hline Very large & 143 & 4.6 \\
\hline Larger than average & 618 & 19.8 \\
\hline Average & 1888 & 60.6 \\
\hline Smaller than average & 337 & 10.8 \\
\hline Very small & 72 & 2.8 \\
\hline Birth weight & 4150 & $3.1(2.8-3.5)$ \\
\hline \multicolumn{3}{|l|}{ Diarrhea episode } \\
\hline Yes & 702 & 24.2 \\
\hline No & 2194 & 75.8 \\
\hline \multicolumn{3}{|l|}{ Fever episode } \\
\hline Yes & 576 & 19.9 \\
\hline No & 2320 & 80.1 \\
\hline \multicolumn{3}{|l|}{ Maternal characteristics } \\
\hline Median age & 2896 & $26(21-32)$ \\
\hline Median age at first child & 2896 & $18(17-20)$ \\
\hline Age at first childbirth & & \\
\hline
\end{tabular}




\begin{tabular}{|c|c|c|}
\hline Characteristic & $\mathbf{N}$ & $\%$ or Median (IQR)* \\
\hline$<19$ & 1242 & 42.9 \\
\hline $19-49$ & 1654 & 57.1 \\
\hline \multicolumn{3}{|l|}{ Education level } \\
\hline No education & 287 & 9.9 \\
\hline Primary & 1531 & 52.9 \\
\hline Secondary & 976 & 33.7 \\
\hline Tertiary & 102 & 3.5 \\
\hline \multicolumn{3}{|l|}{ Literacy level } \\
\hline Yes & 1583 & 54.7 \\
\hline No & 1313 & 45.3 \\
\hline \multicolumn{3}{|c|}{ Household characteristics } \\
\hline \multicolumn{3}{|l|}{ Province } \\
\hline Central & 283 & 9.77 \\
\hline Copperbelt & 227 & 7.84 \\
\hline Eastern & 382 & 13.19 \\
\hline Luapula & 342 & 11.81 \\
\hline Lusaka & 263 & 9.08 \\
\hline Muchinga & 257 & 8.87 \\
\hline Northern & 324 & 11.19 \\
\hline North Western & 230 & 7.94 \\
\hline Southern & 303 & 10.46 \\
\hline Western & 285 & 9.84 \\
\hline \multicolumn{3}{|l|}{ Residence } \\
\hline Rural & 2098 & 72.4 \\
\hline Urban & 798 & 27.6 \\
\hline \multicolumn{3}{|l|}{ Wealth quintile } \\
\hline Poorest & 881 & 30.42 \\
\hline
\end{tabular}




\begin{tabular}{|lll|}
\hline Characteristic & N & \% or Median (IQR) \\
\hline Poorer & 723 & 24.97 \\
\hline Middle & 578 & 19.96 \\
\hline Richer & 391 & 13.5 \\
\hline Richest & 323 & 11.15 \\
\hline Source of drinking water & & \\
\hline Protected & 1779 & 63.0 \\
\hline Unprotected & 1045 & 37.0 \\
\hline Household size & 2896 & $6(4-8)$ \\
\hline Number of children $<5$ years & 2896 & $2(1-2)$ \\
\hline Sex of household head & & \\
\hline Female & 583 & 20.1 \\
\hline Male & 2313 & 79.9 \\
\hline Age of household head & 2896 & $36(29-45)$ \\
\hline * IQR, Interquartile range & & \\
\hline
\end{tabular}

\section{Bivariate analysis}

Results for correlational analysis are presented in Table 2. Breastfeeding duration was negatively correlated with both HAZ $(r=-0.284, p<0.000)$ and WHZ $(r=-0178, p<0.000)$. Other variables associated with both HAZ and WHZ were dietary diversity, wealth index, water source, residence, maternal education, birthweight, perceived birth size, maternal literacy, diarrhea, and fever. Some variables were only associated with HAZ but not WHZ, such as child sex $(r=0.114, p<0.000)$ and bottle feeding $(r=0.041, p$ $=0.029$ ). Variables only correlated with WHZ but not HAZ were maternal marital status, age when the mother had her first child. 
Table 2

Bivariate analysis for HAZ and WHZ.

\begin{tabular}{|c|c|c|}
\hline \multirow[t]{2}{*}{ Variable } & \multicolumn{2}{|c|}{ Anthropometric index } \\
\hline & HAZ & WHZ \\
\hline Dietary diversity & $-0.138^{*}$ & $-0.112^{\star}$ \\
\hline Breastfeeding initiation & -0.002 & -0.030 \\
\hline Age of the Household head & 0.031 & -0.010 \\
\hline Maternal age at first child & -0.030 & $-0.046^{\star}$ \\
\hline Maternal age & 0.014 & $-0.051^{\star}$ \\
\hline Breastfeed duration & $-0.284^{\star}$ & $-0.178 *$ \\
\hline Female sex of child & $0.114^{\star}$ & 0.027 \\
\hline Maternal marital status & -0.009 & $-0.042^{\star}$ \\
\hline Household size & 0.014 & -0.023 \\
\hline Bottle feeding & $0.041 * \star \star$ & -0.002 \\
\hline Number of children U5 & 0.017 & -0.035 \\
\hline Wealth index & $0.118^{*}$ & $0.071^{*}$ \\
\hline Water source $(1=$ safe, $0=$ unsafe $)$ & $0.050 * \star$ & $0.053^{*}$ \\
\hline Residence (Urban/rural) & $-0.068^{*}$ & $-0.051^{\star}$ \\
\hline Maternal education & $0.101 *$ & $0.072^{\star}$ \\
\hline Birthweight & $0.243^{*}$ & $0.119^{*}$ \\
\hline Perceived birth size & $-0.152^{\star}$ & $-0.116^{\star}$ \\
\hline Maternal Literacy & $0.078^{*}$ & $0.042^{*}$ \\
\hline Type of toilet facility & $0.047 \star \star \star \star$ & $0.055^{\star}$ \\
\hline Fever & $-0.081^{*}$ & $-0.056^{\star}$ \\
\hline Diarrhea & $-0.040 *$ & $-0.098^{\star}$ \\
\hline$\star P<0.001, * \star P<0.01, * \star \star<0.05$ & & \\
\hline
\end{tabular}

\section{Multivariate analysis}


After controlling for maternal, child and household characteristics, breastfeeding duration was negatively associated with HAZ $(\beta=-0.07, p<0.001)$ (Table 3$)$. Female sex and birthweight positively predicted HAZ, the latter was the strongest determinant of HAZ among Zambian children under the age of 2 years. The rest of the other variables ceased to be significantly associated with HAZ (Table 3). In secondary analysis, when HAZ was dichotomized to classify children as either stunted or not, breastfeeding duration was independently associated with stunting (Odds ratio $=1.10, p<0.001$ ) after controlling for potential confounders (Supplementary Table 1). On the other hand, an increase in age by one kilogram was associated with $65 \%$ decrease in the odds of stunting (Odds ratio $0.35, p<0.001$ ).

Table 3

Predictors for HAZ for children aged 0 to 23 months from linear regression model

\begin{tabular}{|lllll|}
\hline HAZ & Coefficient. & $\mathbf{P}>\mathbf{t}$ & $95 \% \mathrm{Cl}$ & \\
\hline Dietary diversity & 0.03 & 0.090 & -0.01 & 0.07 \\
\hline Breastfeeding duration & -0.07 & $<0.001$ & -0.08 & -0.06 \\
\hline Female sex & 0.41 & $<0.001$ & 0.31 & 0.52 \\
\hline Bottle feeding & 0.02 & 0.90 & -0.25 & 0.29 \\
\hline Wealth & 0.06 & 0.06 & 0.00 & 0.13 \\
\hline Water source & 0.08 & 0.21 & -0.05 & 0.21 \\
\hline Residence & 0.02 & 0.82 & -0.14 & 0.18 \\
\hline Maternal education in years & 0.08 & 0.13 & -0.02 & 0.19 \\
\hline Birthweight & 0.59 & $<0.001$ & 0.47 & 0.71 \\
\hline Perceived birth size & -0.08 & 0.07 & -0.17 & 0.01 \\
\hline Literacy & 0.01 & 0.83 & -0.12 & 0.15 \\
\hline Toilet facility & -0.03 & 0.66 & -0.15 & 0.10 \\
\hline Fever in the previous two weeks & -0.13 & 0.08 & -0.27 & 0.02 \\
\hline Diarrhea in the previous two weeks & 0.10 & 0.16 & -0.04 & 0.24 \\
\hline
\end{tabular}

Results of the path analysis models are presented in Fig. 1; breastfeeding duration mediated the effects of maternal age $(\beta=0.11, p<0.001)$ and education $(\beta=-0.05, p=0.018)$. On the other hand, breastfeeding duration continued to directly affect HAZ scores. The direct, indirect and total effects of variables on HAZ scores are presented in Table 4. Birthweight had a non-significant effect on breastfeeding duration, indicative of absence of reverse causality, but had the strongest direct and indirect effects on HAZ-scores than all the other covariates. 
Table 4

Standardized effects of the variables on HAZ-Scores from the path analysis

\begin{tabular}{|llll|}
\hline Variable & Effects & \\
\hline Breastfeeding duration & Direct & Indirect & Total \\
\hline Birth weight & $-0.06^{*}$ & & $-0.06^{\star}$ \\
\hline Maternal age & $0.64^{\star}$ & -0.001 & $0.64^{\star}$ \\
\hline Maternal education & 0.00 & 0.002 & 0.007 \\
\hline Female sex & $0.11^{\star}$ & 0.027 & $0.134^{\star}$ \\
\hline Residence & $0.41^{\star}$ & $-0.04^{*}$ & $0.368^{\star}$ \\
\hline Household wealth index & 0.02 & & 0.023 \\
\hline Number of children under the age of five years & 0.01 & & 0.01 \\
\hline
\end{tabular}

\section{Predictors for weight-for-height}

Controlling for potential confounding factors, breastfeeding duration $(\beta=-0.04, p<0.001)$, maternal age, children under the age of five, and diarrhea were all negatively associated with WHZ while birth weight was a positive determinant of WHZ among children under the age of five (Supplementary Table 2).

\section{Discussion}

The present study was designed to assess the relationship between breastfeeding duration and nutritional status among children aged 0 to 23 months. Among Zambian infants and young children, breastfeeding duration was inversely associated with HAZ after controlling for potential child, maternal and household confounders. Other than breastfeeding duration, birth weight was the strongest predictor of HAZ among children under the age of 24 months. Additionally, being female was positively associated with HAZ. Using stunting as an outcome variable, breastfeeding duration increased the odds of stunting among children. Similar findings were observed between breastfeeding duration and WHZ. Apart from breastfeeding duration, birth weight and child sex were the other variables significantly associated with both HAZ and WHZ. Diarrhea episode in the previous two weeks was only associated with WHZ.

Our finding that duration of breastfeeding is negatively associated with nutritional status among children is in line with findings from other low- and middle-income countries. In a prospective cohort study conducted by Fall, Sachdev (16), breastfeeding duration was negatively correlated with HAZ among South African and Filipino infants and young children. Similarly, among Pakistani (17) breastfeeding 
duration was negatively associated with lower HAZ and height respectively among children. In an earlier analysis, Caulfield, Bentley (11) also observed a positive association between prolonged breastfeeding and malnutrition among child less than three years old. Our results on breastfeeding duration and HAZ are not in agreement with findings among Nepalese (18) and Guatemalan (16) children, in whom breastfeeding duration was shown to be positively associated with HAZ. The differences in the results could be due to failure to account for confounding in some studies or mediating factors such as age of the children. It may as well be due to reverse causality, children perceived to be smaller and shorter are likely to be breastfed longer than their taller counterparts $(13,19)$. In the present study we controlled for potential confounding and we explored mediation as well as possibility for reverse causality using path analysis. The latter was not evidence in our study.

Our study demonstrates that being female among Zambian children under the age of 24 months was associated with greater HAZ. Similar findings have been reported among African countries. In a metaanalysis on the determinants of stunting and obesity among children in sub-Saharan Africa, Keino, Plasqui (20) demonstrated higher prevalence of stunting among boys than girls, confirming what was reported by Wamani, Astrom (21). The similar findings have recently been observed in Tanzania (22) and Ethiopia (23). The differential sex growth may be related to differences in feeding and care practices for boys and girls or morbidity, the former was observed among Senegalese children younger than three years (24). There is also some evidence that the differences may be linked to differences in the biology of growth between boys and girls (25). Overall, there is currently no universally agreed plausible explanation for the differential sex growth outcomes for children under the age of five years. Further research is need unequivocally elucidate the mechanisms explaining sex differences with respect to malnutrition between boys and girls. Such evidence may prove quite beneficial in public health nutrition programming.

The strongest determinant of HAZ in our study was birthweight. Our results confirm results from earlier studies demonstrating the association between birth weight and HAZ among children (26). The positive association between birth weight and height is also evident beyond childhood. A study among Brazilian adolescents demonstrated an increase of $0.28 \mathrm{~cm}$ in height corresponding to an increase of $100 \mathrm{~g}$ in birth weight (27). Similarly, Jelenkovic, Yokoyama (28) demonstrated birth weight was significantly associated with height from infancy up to adulthood among twins. The mechanisms underlying the association between birth weight and height remain less elucidated. However, it is speculated that intrauterine conditioning may partly explain the associations observed postnatally (29) .

Birth weight was the strongest and only positive determinant of $\mathrm{WHZ}$ in our sample. Similar association have previously been reported from nationally representative samples (30). Apart from breastfeeding duration, the other factors negatively associated with WHZ were episode of diarrhea in the last two weeks and maternal age. Our results on diarrhea are in line with findings from other countries from sub-Saharan Africa. Masibo and Makoka (31) and Wasihun, Dejene (32) observed an inverse relationship between diarrhea episode and wasting among Kenyan and Ethiopian children under the age of five respectively. Diarrhea can lead to undernutrition through impaired appetite, malabsorption, acute phase catabolism (33). The negative association between maternal age and $\mathrm{WHZ}$ is in contrast with evidence from other 
studies both in sub-Saharan Africa (34). The difference between our results and those showing a positive association may be due to differential socioeconomic mechanisms operating in different environment (35).

The present study has several of strengths including large sample size, robust statistical approach to account for confounding, effect modification, and mediation. The main weaknesses of the study were failure to control for maternal height, which is a positive predictor of HAZ for children; potential for recall bias for variables measured using maternal memory and cross-sectional design rendering it difficult to ascertain causality. Finally, the effect of residual confounding may not be ruled out. Overall, taken together the present study has demonstrated that breastfeeding duration is negatively associated with growth outcomes among children, however, the effect is unlikely to be of clinical importance.

\section{Conclusion}

Our study has demonstrated that breastfeeding duration is negatively associated with both HAZ and $\mathrm{WHZ}$ among Zambian children. However, the magnitudes of the association were quite small to be of clinical significance. Thus, breastfeeding should continue to be protected and supported from birth up to two years and beyond.

\section{List Of Abbreviations}

IQR, Interquartile range

HAZ Height-for-age z-score

SD Standard deviation

WAZ Weight-for-length and weight-for-height z-score

ZDHS Zambia demographic and health survey

ZSA Zambia Statistics Agency

\section{Declarations}

\section{Ethics approval and consent to participate}

The authors got permission from DHS program to use the ZDHS data that were accessible via:

https://www.dhsprogram.com/data/dataset_admin/login_main.cfm. The DHS obtained ethical clearance from relevant national ethics bodies before collecting the data.

\section{Consent for publication}

Not applicable 
Availability of data and materials

The main data set used for the present analysis was obtained from the Demographic and Health Survey Program is available from the https://www.dhsprogram.com/data/dataset_admin/login_main.cfm. However, sharing of these data to a third party is not allowed. The weighted date used for preparing the current manuscript may be obtained from the corresponding author upon reasonable request and with permission of DHS Program.

\section{Competing interests}

The authors declare that they have no competing interests

\section{Funding}

Authors did not receive funding for the present work.

\section{Authors' contributions}

CK conceptualized the study, performed data analysis and drafted the manuscript. LMZ, MU, DN, HNS and KA contributed in writing the manuscript. All authors read and approved the final manuscript.

\section{Acknowledgements}

Not applicable

\section{References}

1. Victora CG, Bahl R, Barros AJ, Franca GV, Horton S, Krasevec J, et al. Breastfeeding in the 21st century: epidemiology, mechanisms, and lifelong effect. Lancet. 2016 Jan 30;387(10017):475-90. PubMed PMID: 26869575.

2. Gartner LM, Morton J, Lawrence RA, Naylor AJ, O'hare D, Schanler RJ, et al. Breastfeeding and the use of human milk. Pediatrics. 2005 Feb;115(2):496-506. PubMed PMID: 15687461.

3. Bhutta ZA, Das JK, Rizvi A, Gaffey MF, Walker N, Horton S, et al. Evidence-based interventions for improvement of maternal and child nutrition: what can be done and at what cost? Lancet. 2013 Aug 3;382(9890):452-77. PubMed PMID: 23746776.

4. Roberts TJ, Carnahan E, Gakidou E. Can breastfeeding promote child health equity? A comprehensive analysis of breastfeeding patterns across the developing world and what we can learn from them. BMC medicine. 2013 Dec 4;11:254. PubMed PMID: 24305597. Pubmed Central PMCID: 3896843.

5. Black RE, Allen LH, Bhutta ZA, Caulfield LE, De Onis M, Ezzati M, et al. Maternal and child undernutrition: global and regional exposures and health consequences. Lancet. 2008 Jan 19;371(9608):243-60. PubMed PMID: 18207566. 
6. Zambia Statistics Office, Ministry Of Health , Icf. Zambia demographic and health survey 2018. Lusaka: Central Statistical Office, Ministry of Health, and ICF International ...; 2019.

7. Ballard O, Morrow AL. Human milk composition: nutrients and bioactive factors. Pediatric clinics of North America. 2013 Feb;60(1):49-74. PubMed PMID: 23178060. Pubmed Central PMCID: 3586783.

8. Eriksen KG, Christensen SH, Lind MV, Michaelsen KF. Human milk composition and infant growth. Current opinion in clinical nutrition and metabolic care. 2018 May;21(3):200-6. PubMed PMID: 29461264.

9. Kramer MS, Matush L, Vanilovich I, Platt RW, Bogdanovich N, Sevkovskaya Z, et al. Effects of prolonged and exclusive breastfeeding on child height, weight, adiposity, and blood pressure at age $6.5 \mathrm{y}$ : evidence from a large randomized trial. The American journal of clinical nutrition. 2007 Dec;86(6):1717-21. PubMed PMID: 18065591.

10. Owen CG, Martin RM, Whincup PH, Davey-Smith G, Gillman MW, Cook DG. The effect of breastfeeding on mean body mass index throughout life: a quantitative review of published and unpublished observational evidence. The American journal of clinical nutrition. 2005 Dec;82(6):1298307. PubMed PMID: 16332664.

11. Caulfield LE, Bentley ME, Ahmed S. Is prolonged breastfeeding associated with malnutrition? Evidence from nineteen demographic and health surveys. Int J Epidemiol. 1996 Aug;25(4):693-703. PubMed PMID: 8921445.

12. Kramer MS. Breastfeeding, complementary (solid) foods, and long-term risk of obesity. The American journal of clinical nutrition. 2010 Mar;91(3):500-1. PubMed PMID: 20107200.

13. Marquis GS, Habicht JP, Lanata CF, Black RE, Rasmussen KM. Association of breastfeeding and stunting in Peruvian toddlers: an example of reverse causality. Int J Epidemiol. 1997 Apr;26(2):34956. PubMed PMID: 9169170.

14. Bell BA, Onwuegbuzie AJ, Ferron JM, Jiao QG, Hibbard ST, Kromrey JD. Use of design effects and sample weights in complex health survey data: a review of published articles using data from 3 commonly used adolescent health surveys. American journal of public health. 2012 Jul;102(7):1399405. PubMed PMID: 22676502. Pubmed Central PMCID: 3477989.

15. Alderman $\mathrm{H}$, Headey $\mathrm{D}$. The timing of growth faltering has important implications for observational analyses of the underlying determinants of nutrition outcomes. PloS one. 2018;13(4):e0195904. PubMed PMID: 29694431. Pubmed Central PMCID: 5919068.

16. Fall CH, Sachdev HS, Osmond C, Restrepo-Mendez MC, Victora C, Martorell R, et al. Association between maternal age at childbirth and child and adult outcomes in the offspring: a prospective study in five low-income and middle-income countries (COHORTS collaboration). The Lancet Global health. 2015 Jul;3(7):e366-77. PubMed PMID: 25999096. Pubmed Central PMCID: 4547329.

17. Chaudhary SR, Govil S, Lala MK, Yagnik HB. Infant and Young Child Feeding Index and its association with nutritional status: A cross-sectional study of urban slums of Ahmedabad. Journal of family \& community medicine. 2018 May-Aug;25(2):88-94. PubMed PMID: 29922108. Pubmed Central PMCID: 5958529. 
18. Hanley-Cook G, Argaw A, Dahal P, Chitekwe S, Kolsteren P. Infant and young child feeding practices and child linear growth in Nepal: Regression-decomposition analysis of national survey data, 19962016. Maternal \& child nutrition. 2020 Jan 10:e12911. PubMed PMID: 31922348.

19. Simondon KB, Costes R, Delaunay V, Diallo A, Simondon F. Children's height, health and appetite influence mothers' weaning decisions in rural Senegal. Int J Epidemiol. 2001 Jun;30(3):476-81. PubMed PMID: 11416068.

20. Keino S, Plasqui G, Ettyang G, van den Borne B. Determinants of stunting and overweight among young children and adolescents in sub-Saharan Africa. Food and nutrition bulletin. 2014 Jun;35(2):167-78. PubMed PMID: 25076764.

21. Wamani H, Astrom AN, Peterson S, Tumwine JK, Tylleskar T. Boys are more stunted than girls in subSaharan Africa: a meta-analysis of 16 demographic and health surveys. BMC pediatrics. $2007 \mathrm{Apr}$ 10;7:17. PubMed PMID: 17425787. Pubmed Central PMCID: 1865375.

22. Muhimbula $\mathrm{H}$, Kinabo J, O'Sullivan A. Determinants of infant nutrition status in rural farming households before and after harvest. Maternal \& child nutrition. 2019 Jul;15(3):e12811. PubMed PMID: 30897661. Pubmed Central PMCID: 7199042.

23. Amare $Z Y$, Ahmed ME, Mehari AB. Determinants of nutritional status among children under age 5 in Ethiopia: further analysis of the 2016 Ethiopia demographic and health survey. Globalization and health. 2019 Nov 6;15(1):62. PubMed PMID: 31694661. Pubmed Central PMCID: 6836473.

24. Bork KA, Diallo A. Boys Are More Stunted than Girls from Early Infancy to 3 Years of Age in Rural Senegal. The Journal of nutrition. 2017 May;147(5):940-7. PubMed PMID: 28298540.

25. Thurstans S, Opondo C, Seal A, Wells J, Khara T, Dolan C, et al. Boys are more likely to be undernourished than girls: a systematic review and meta-analysis of sex differences in undernutrition. BMJ global health. 2020 Dec;5(12). PubMed PMID: 33328202. Pubmed Central PMCID: 7745319.

26. Binkin NJ, Yip R, Fleshood L, Trowbridge FL. Birth weight and childhood growth. Pediatrics. 1988 Dec;82(6):828-34. PubMed PMID: 3186371.

27. Ferreira VR, Jardim TV, Povoa TR, Mendonca KL, Nascente FN, Carneiro CS, et al. Birth weight and its association with blood pressure and nutritional status in adolescents. Jornal de pediatria. $2018 \mathrm{Mar}$ Apr;94(2):184-91. PubMed PMID: 28843059.

28. Jelenkovic A, Yokoyama Y, Sund R, Hur YM, Harris JR, Brandt I, et al. Associations between birth size and later height from infancy through adulthood: An individual based pooled analysis of 28 twin cohorts participating in the CODATwins project. Early human development. 2018 May;120:53-60. PubMed PMID: 29656171. Pubmed Central PMCID: 6532975.

29. Strauss RS. Effects of the intrauterine environment on childhood growth. British medical bulletin. 1997 Jan;53(1):81-95. PubMed PMID: 9158286.

30. McGovern ME. How much does birth weight matter for child health in developing countries? Estimates from siblings and twins. Health economics. 2019 Jan;28(1):3-22. PubMed PMID: 30239053. 
31. Masibo PK, Makoka D. Trends and determinants of undernutrition among young Kenyan children: Kenya Demographic and Health Survey; 1993, 1998, 2003 and 2008-2009. Public health nutrition. 2012 Sep;15(9):1715-27. PubMed PMID: 22694984.

32. Wasihun AG, Dejene TA, Teferi M, Marugan J, Negash L, Yemane D, et al. Risk factors for diarrhoea and malnutrition among children under the age of 5 years in the Tigray Region of Northern Ethiopia. PloS one. 2018;13(11):e0207743. PubMed PMID: 30475875. Pubmed Central PMCID: 6257922.

33. Guerrant RL, Oria RB, Moore SR, Oria MO, Lima AA. Malnutrition as an enteric infectious disease with long-term effects on child development. Nutr Rev. 2008 Sep;66(9):487-505. PubMed PMID: 18752473. Pubmed Central PMCID: 2562291.

34. Wemakor A, Garti H, Azongo T, Garti H, Atosona A. Young maternal age is a risk factor for child undernutrition in Tamale Metropolis, Ghana. BMC research notes. 2018 Dec 10;11(1):877. PubMed PMID: 30526641. Pubmed Central PMCID: 6288872.

35. Finlay JE, Ozaltin E, Canning D. The association of maternal age with infant mortality, child anthropometric failure, diarrhoea and anaemia for first births: evidence from 55 low- and middleincome countries. BMJ open. 2011 Jan 1;1(2):e000226. PubMed PMID: 22021886. Pubmed Central PMCID: 3191600.

\section{Figures}

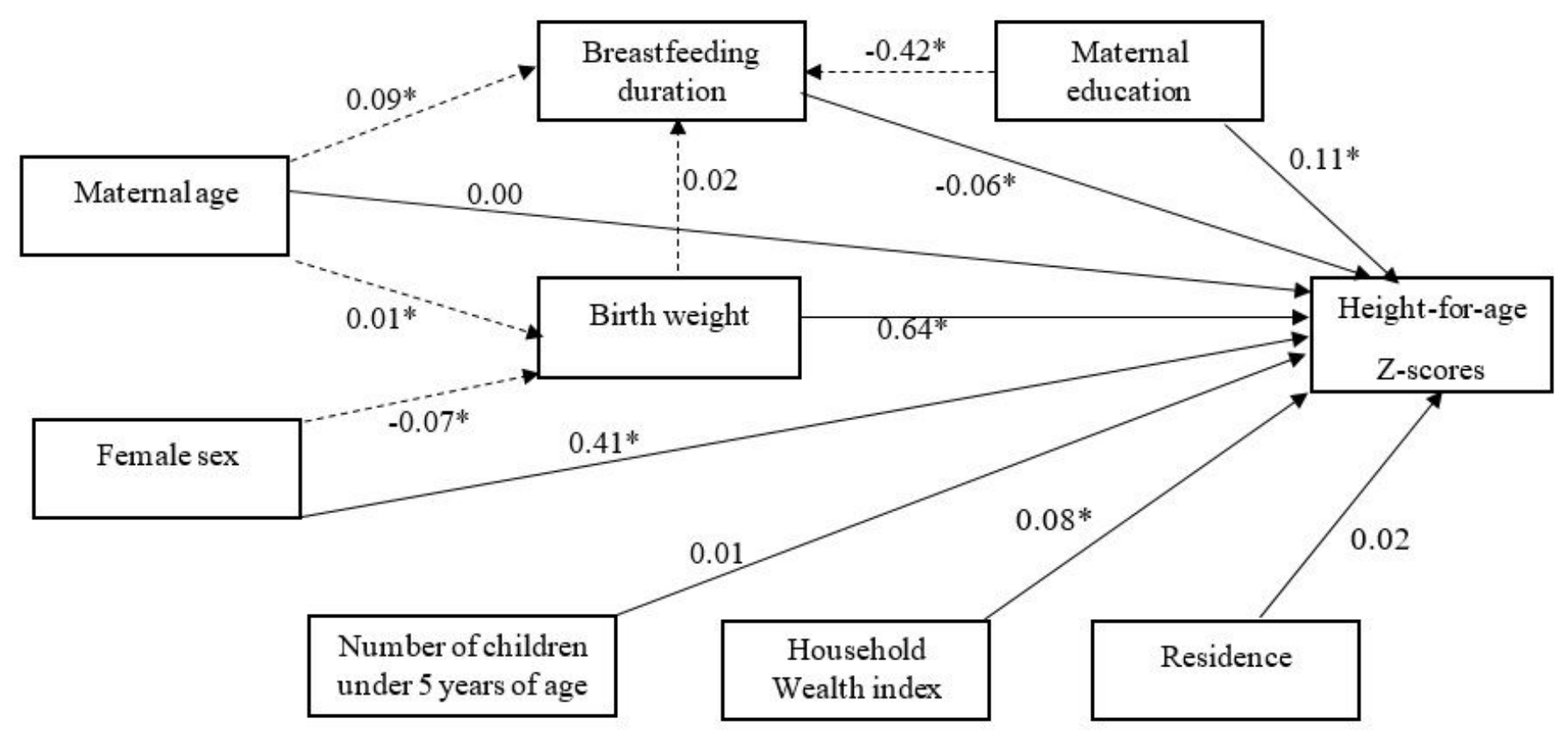

\section{Figure 1}

Path analysis for HAZ-Scores and independent variables. *Variables significantly related to Height-for-age $(P<0.01)$. All coefficients shown are standardized regression coefficients. Dashed lines show 
relationships between covariates, while solid lines show relationships between height-for-age and covariates.

\section{Supplementary Files}

This is a list of supplementary files associated with this preprint. Click to download.

- SupplementalTables.docx 